\title{
Effect of Porosity on the Tensile Properties of Low Ductility Aluminum Alloys
}

\author{
Gustavo Waldemar Mugica ${ }^{\text {a*, Daniel Oscar Tovio }}{ }^{\mathrm{a}}$, \\ Julio César Cuyas ${ }^{\mathrm{a}}$,Aulio César González \\ ${ }^{a}$ Laboratorio de Investigaciones en Metalurgia Física, Facultad de Ingeniería \\ Universidad Nacional de La Plata, Calle 48 esq. 116 (1900) La Plata, Argentina \\ ${ }^{\mathrm{b}}$ Facultad de Ingeniería, Universidad Nacional de la Plata. Consejo Nacional de \\ Investigaciones Científicas Técnicas, Calle 48 esq. 116 (1900). La Plata, Argentina
}

Received: May 27, 2002; Revised: November 10, 2003

\begin{abstract}
The literature contains reports of several studies correlating the porosity and mechanical properties of aluminum alloys. Most of these studies determine this correlation based on the parameter of global volumetric porosity. These reports, however, fail to separate the effects of microstructural features and porosity on alloys, though recognizing the influence of the latter on their mechanical properties. Thus, when the decrease in tensile strength due to the porosity effect is taken into account, the findings are highly contradictory. An analysis was made of the correlation between mechanical properties and global volumetric porosity and volumetric porosity in the fracture, as well as of the $\beta-\mathrm{Al}_{5} \mathrm{FeSi}$ phase present in 380 aluminum alloy. Our findings indicate that mechanical properties in tension relating to global volumetric porosity lead to overestimations of the porosity effect in detriment to the mechanical properties. Moreover, the proposed models that take into account the effects of particles, both $\mathrm{Si}$ and $\beta-\mathrm{Al}_{5} \mathrm{FeSi}$, are unapplicable to low ductility alloys.
\end{abstract}

Keywords: aluminum, foundry, porosity, mechanical properties

\section{Introduction}

Several studies in the literature correlate the porosity and mechanical properties of cast aluminum alloys ${ }^{1-5}$ and most of these studies use the parameter of global volumetric porosity to determine this correlation.

Apart from the porosity effect, the mechanical properties of these alloys generally result from a set of variables such as chemical composition ${ }^{6,7}$, morphology and size of eutectic silicium ${ }^{8}$, type and shape of intermetallic particles of iron ${ }^{9,10}$, particularly $\beta-\mathrm{Al}_{5} \mathrm{FeSi}$ phase, and dendritic cell size. Thus, when the decrease in tensile strength due to the effect of porosity is taken into account, the results are highly inconsistent ${ }^{11}$.

Among the reports analyzed in ref. 11 by the authors, the aforementioned effects of the microstructural properties were not separated from the effect of porosity, although the influence of the former on the mechanical properties is recognized. This leads to very different results, as can be seen in Table 1. The $\Delta \mathrm{UTS}$ listed in this table indicate the deterioration of tensile strength caused by the effect of porosity in 356 aluminum alloy, according to Radhakrisna ${ }^{2}$ and $\operatorname{Pan}^{12}$. Similar results were found for elongation in ref. 11, by the same authors, and for alloy, indicated in Table 1 , and by two other authors for 319 aluminum alloy.

Some authors ${ }^{5,6}$ state that, when the mechanical properties and global volumetric porosity are correlated, the dispersion value decreases if the porosity is measured in the fracture plane.

Although this subject is not new, two aspects in the present work are conspicuous. First, even though the use of 380 aluminum alloy has long been widespread, information on the subject is scarce compared with that on 356 and 319 aluminum alloys. Second, and more important, is that experiments were carried out on two different compositions under conditions such that only the porosity was altered while the remaining microstructural characteristics that could affect the mechanical properties remained constant.

*e-mail: gmugica@ing.unlp.edu.ar 
Table 1. Detrimental effect on tensile strength obtained by Pan and Radhakrishna's equation for 356 aluminum alloy.

\begin{tabular}{ccc}
\hline Porosity\% & \multicolumn{2}{c}{$\Delta \mathrm{UTS}(\mathrm{MPa})$} \\
& Radhakrishna & Pan \\
\hline 1 & -69.9 & -20.2 \\
2 & -124.0 & -40.4 \\
3 & -162.3 & 60.6 \\
4 & -184.8 & -80.8 \\
\hline
\end{tabular}

Of all the bibliography reviewed here, only Eady and Smith $^{12}$, who worked with 356 aluminum alloy, considered conditions similar to the abovementioned ones. To reach these conditions, we used the same type of mold (dimensions and materials), the same temperature and the same cast procedure, which resulted in the same thermal cycle for all the material used to manufacture our pieces. The degassing grade was modified to obtain different values of porosity.

The correlation between mechanical properties, global volumetric porosity and volumetric porosity in the fracture was analyzed, as was the presence of $\beta-\mathrm{Al}_{5} \mathrm{FeSi}$ phase.

In this paper, the expressions "global volumetric porosity" and "volumetric porosity in the fracture" are used to distinguish the porosity measurements taken from the whole tension tested piece, and the porosity determined from small specimens of material close to the fracture.

\section{Experimental Procedure}

The two 380 aluminum alloy compositions used in this study are listed in Table 2, together with the standard composition given by the Aluminum Association (AA).

Mechanical properties such as tensile strength, yield strength, and elongation were studied. To this end, plates of each composition, alloy 1 and alloy 2 (see Table 2), were obtained without adding eutectic modifiers or grain refiners. These were cast in sand molds, using a cast pouring temperature of $750 \pm 5{ }^{\circ} \mathrm{C}$ in each case.

Figure 1 shows a diagram of the plate and its corresponding measurements. To obtain a laminar flow of the liquid during casting, the mold was placed at an angle of about $50^{\circ}$ in relation to the horizontal position and raised to a ver- tical position during pouring. The different grades of porosity were obtained by means of different degassing times, using two gases: $\mathrm{N}_{2} 99.99 \%$ and $\mathrm{N}_{2} 99.00 \%$, injected with a static graphite nozzle with a porous plug ${ }^{13}$.

Each sample's global volumetric porosity and volumetric porosity in the fracture were obtained by means of a

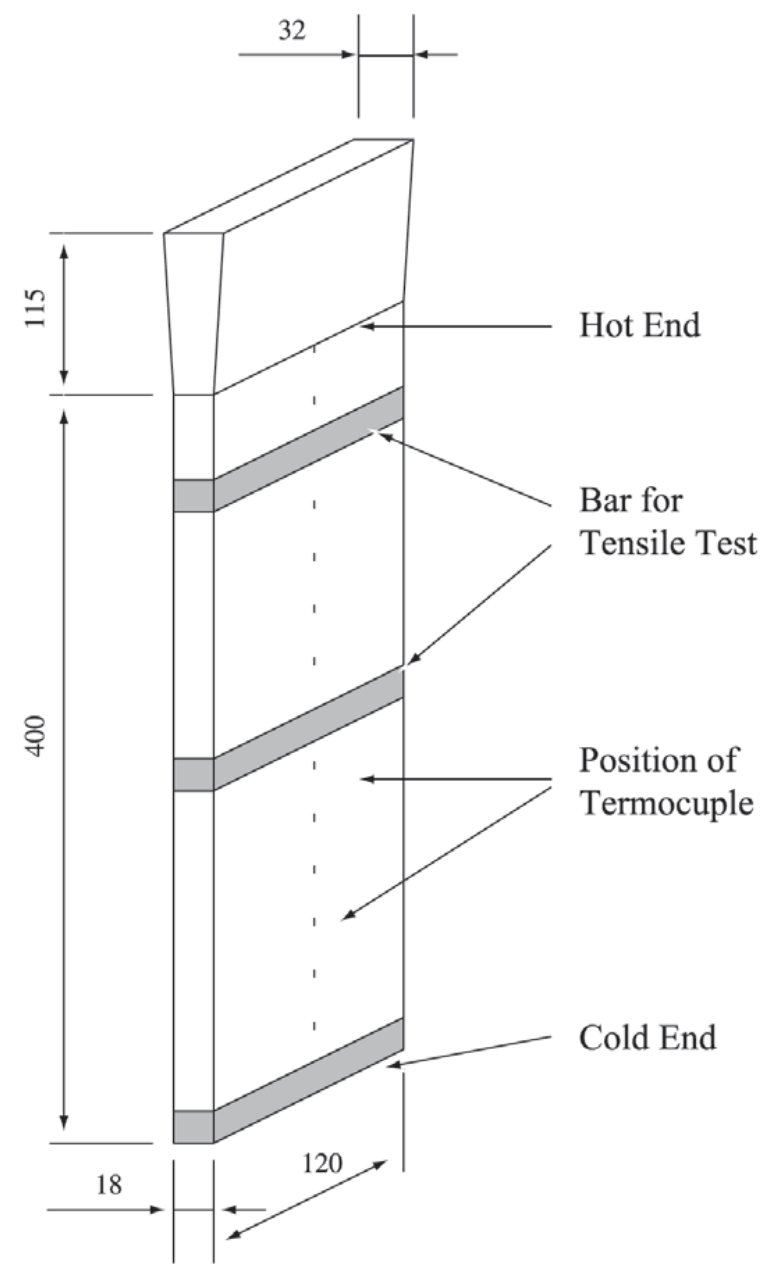

Figure 1. Diagram of the plate. The dots indicate the position of thermocouples used for measuring the cooling rate.

Table 2. Chemical compositions of 380 aluminum alloys.

\begin{tabular}{ccccccccc}
\hline & \multicolumn{9}{c}{ Composition (\% in weight) } & & & \\
& $\mathrm{Si}$ & $\mathrm{Fe}$ & $\mathrm{Mg}$ & $\mathrm{Mn}$ & $\mathrm{Cu}$ & $\mathrm{Zn}$ & $\mathrm{Ni}$ & $\mathrm{Sn}$ \\
\hline A.A. standard & $7.5-9.5$ & 2.0 & 0.10 & 0.50 & $3.0-4.0$ & 3.0 & 0.50 & 0.35 \\
Alloy 1 & 8.21 & 0.75 & 0.01 & 0.32 & 3.47 & 1.38 & 0.02 & 0.02 \\
Alloy 2 & 9.17 & 0.99 & 0.02 & 0.30 & 3.12 & 0.78 & 0.02 & 0.02 \\
\hline
\end{tabular}


differential weighing technique in air and water and were compared with a standard sample cast in a large mass permanent $\mathrm{Cu}$ mold.

To determine the global volumetric porosity, $18 \times 18 \times 120 \mathrm{~mm}$ bars were cut perpendicularly to the longest axis of the plate and at different distances from the cold end (Fig. 1). Specimens were taken from these bars for tensile tests, which were performed in an Instron machine with $5.000 \mathrm{~kg}$ maximum load and a head displacement speed of $1 \mathrm{~mm} / \mathrm{min}$. The size of the test specimens corresponded to the ASTM A370 standard for $8.75 \mathrm{~mm}$ diameter test specimens.

The cooling rate was measured at various distances from the cold end. For this purpose, highly sensitive K-type thermocouples were used in the central area of the plate, as illustrated in Fig. 1. Data were recorded using an data acquisition device connected to a computer. The cooling rate was

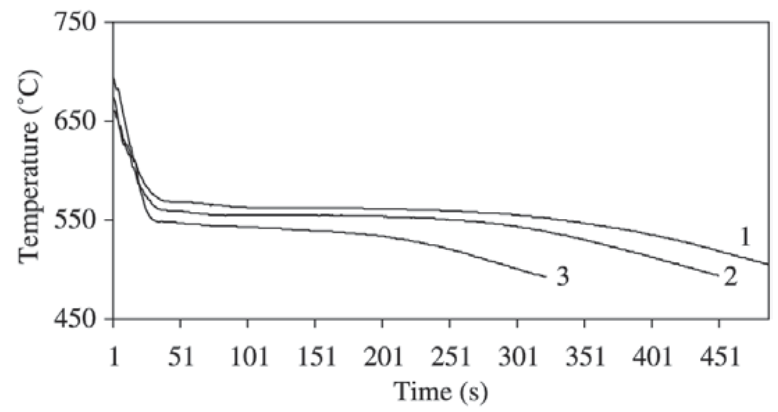

Figure 2. Cooling curves for different distances from the of cold end: 1) $23 \mathrm{~mm}$; 2) $223 \mathrm{~mm}$; 3) $398 \mathrm{~mm}$. calculated in the portion of the curve between the liquidus and eutectic Al-Si temperatures.

Metallographic samples were taken in the central area of the plates and the dendritic cell sizes were measured using an image analysis system.

\section{Results}

\subsection{Cooling rate and dendritic cell size:}

The interdendritic space, which is dependent on the cooling rate, can usually be expressed by the following equation ${ }^{14}$.

$$
\mathrm{DAS}=\mathrm{a} \cdot \varepsilon^{-\mathrm{m}}
$$

where a and $\mathrm{m}$ are constants which vary with the alloy composition, and $\varepsilon$ is the cooling rate.

The cooling curves depicted in Fig. 2 were taken at 43, 223 and $398 \mathrm{~mm}$ from the cold end of the plate. The calcu-

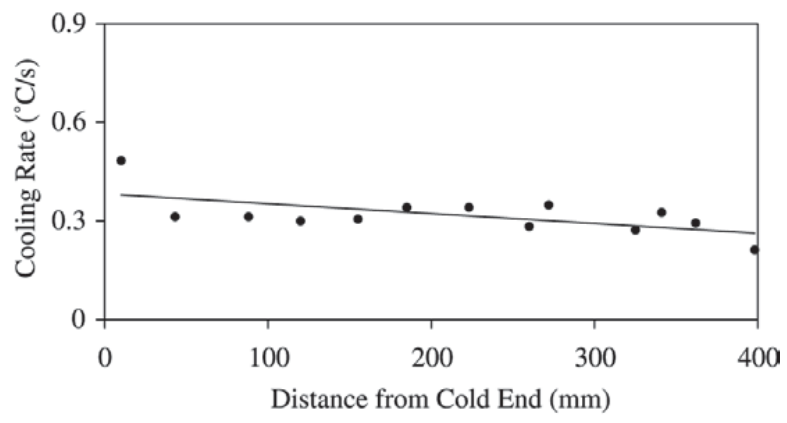

Figure 3. Correlation between cooling rate and distance from the cold end.

Table 3. Grain and dendritic cell sizes of the two compositions at different distances from the plate's cold end.

\begin{tabular}{lccccc}
\hline $\begin{array}{l}\text { Alloy 1 } \\
\begin{array}{l}\text { Distance from } \\
\text { Extreme Cold }(\mathrm{mm})\end{array}\end{array}$ & D.E.*(mm) & $\begin{array}{c}\text { Dendritic } \\
\text { Cell Size }(\mu \mathrm{m})\end{array}$ & $\begin{array}{c}\text { Distance from } \\
\text { Extreme Cold }(\mathrm{mm})\end{array}$ & $\begin{array}{c}\text { Alloy } 2 \\
\text { D.E.*(mm) }\end{array}$ & $\begin{array}{c}\text { Dendritic } \\
\text { Cell Size }(\mu \mathrm{m})\end{array}$ \\
\hline 10 & 4.8 & 34.4 & 5 & 4.8 & - \\
30 & 5.3 & 35.3 & 45 & 4.6 & 29.95 \\
60 & 4.7 & 33.0 & 75 & 4.7 & 29.86 \\
95 & 5.0 & 32.4 & 115 & 4.6 & 29.11 \\
130 & 4.7 & 36.3 & 150 & 4.5 & 27.70 \\
170 & 5.2 & 32.7 & 185 & 4.7 & 28.79 \\
200 & 5.2 & 35.5 & 220 & 4.8 & 25.76 \\
230 & - & 36.2 & 255 & 4.8 & 28.42 \\
270 & 5.2 & 37.0 & 290 & 4.8 & 27.62 \\
300 & 5.1 & 34.4 & 325 & 4.7 & 26.74 \\
340 & 4.9 & 36.7 & 380 & 4.5 & 30.21 \\
360 & 5.1 & 34.0 & 390 & 4.8 & 30.12 \\
395 & 4.4 & 49.1 & 395 & - & \\
\hline
\end{tabular}

*D.E.: grain size in equivalent diameter. 
lated cooling rates are represented in Fig. 3 as a function of their distance from the plate's cold end.

Table 3 gives the results of the dendritic cell size measured at different distances from the cold end of the plate. The measurements are the result of the average of at least 300 calculations carried out in at least 15 different fields in each sample.

The results obtained here indicate that the cell size measured at different distances from the cold end were practi-

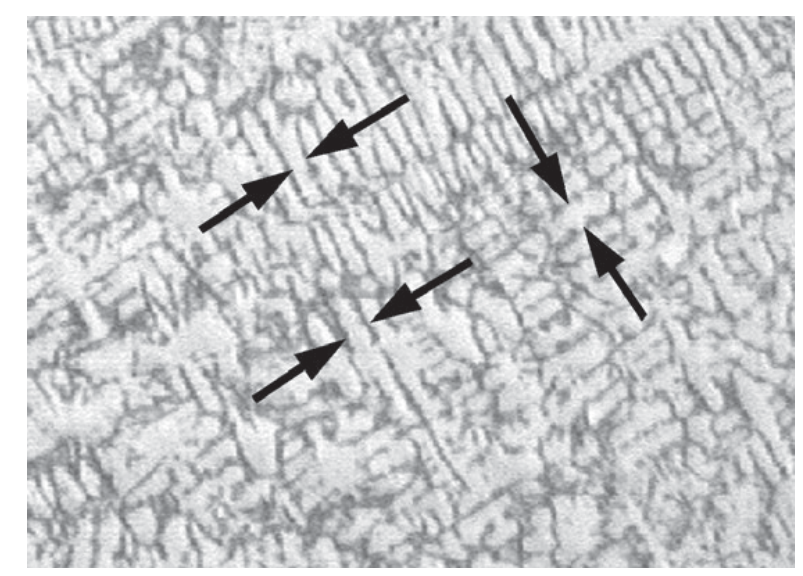

Figure 4. Photomicrography showing the dendritic cell measurements given in Table 2. cally identical, except for the sample taken near the hot end, where the cell size may be significantly larger than in the rest of the plate. This material was excluded from all the plates.

The metallographic image in Fig. 4 indicates how the measurements listed in Table 3 were taken.

\subsection{Volumetric porosity and mechanical properties:}

Figure 5 shows the behavior of tensile strength, yield strength and elongation versus global volumetric porosity.

Figure 6a shows the behavior of tensile strength, yield strength and elongation versus the volumetric porosity in the fracture.

Figure $6 \mathrm{~b}$ illustrates the tensile strength, corrected by porosity according to the "effective diameter" criterion proposed by Surappa et. al. ${ }^{5}$

The shape factor 1.5 was used here for the pores, which corresponded to the average value for the pores making up $85 \%$ of the total area of porosity.

This figure also shows the yield strength corrected by the area lost due to the porosity in each test specimen close to the fracture.

\section{3. $\beta$-Al $\mathrm{FeSi}$ phase:}

The $\beta-\mathrm{Al}_{5} \mathrm{FeSi}$ phase content in the two compositions was significantly different because of the iron content in each alloy. The micrographs in Fig. 7a and 7b, below, corroborate this statement.

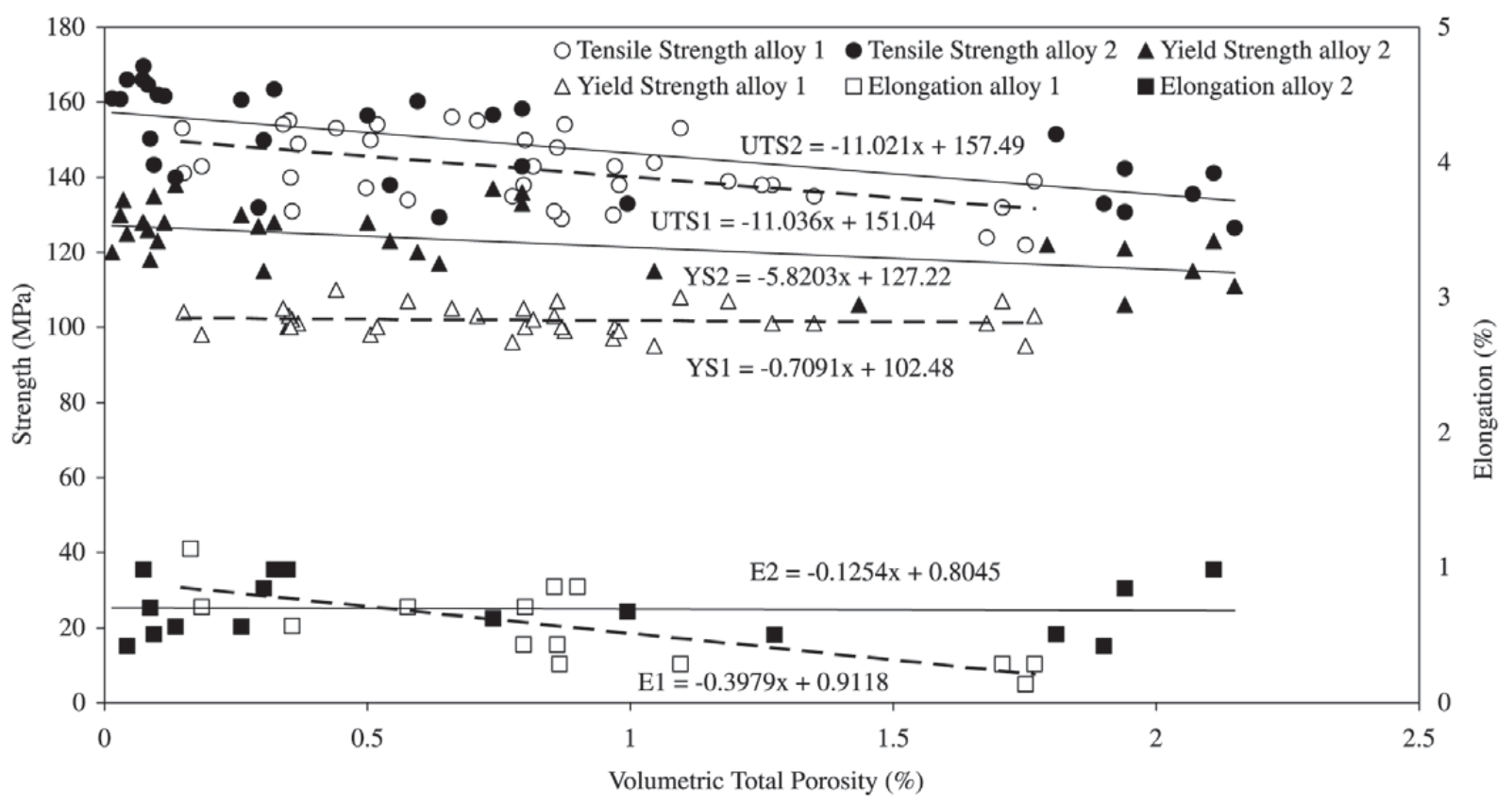

Figure 5. Tensile strength, yield strength and elongation rate as a function of volumetric porosity for the two alloys. 


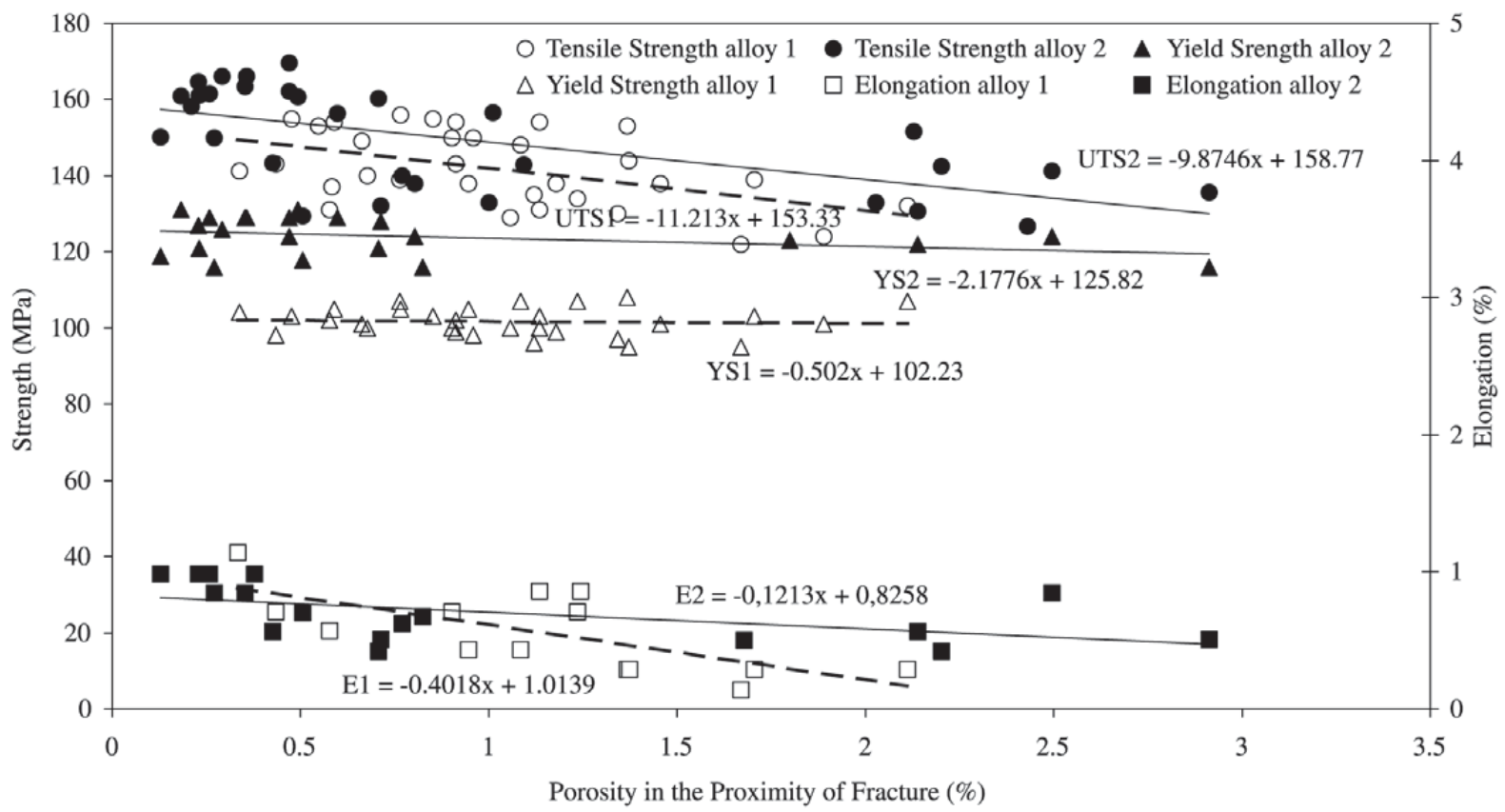

a)

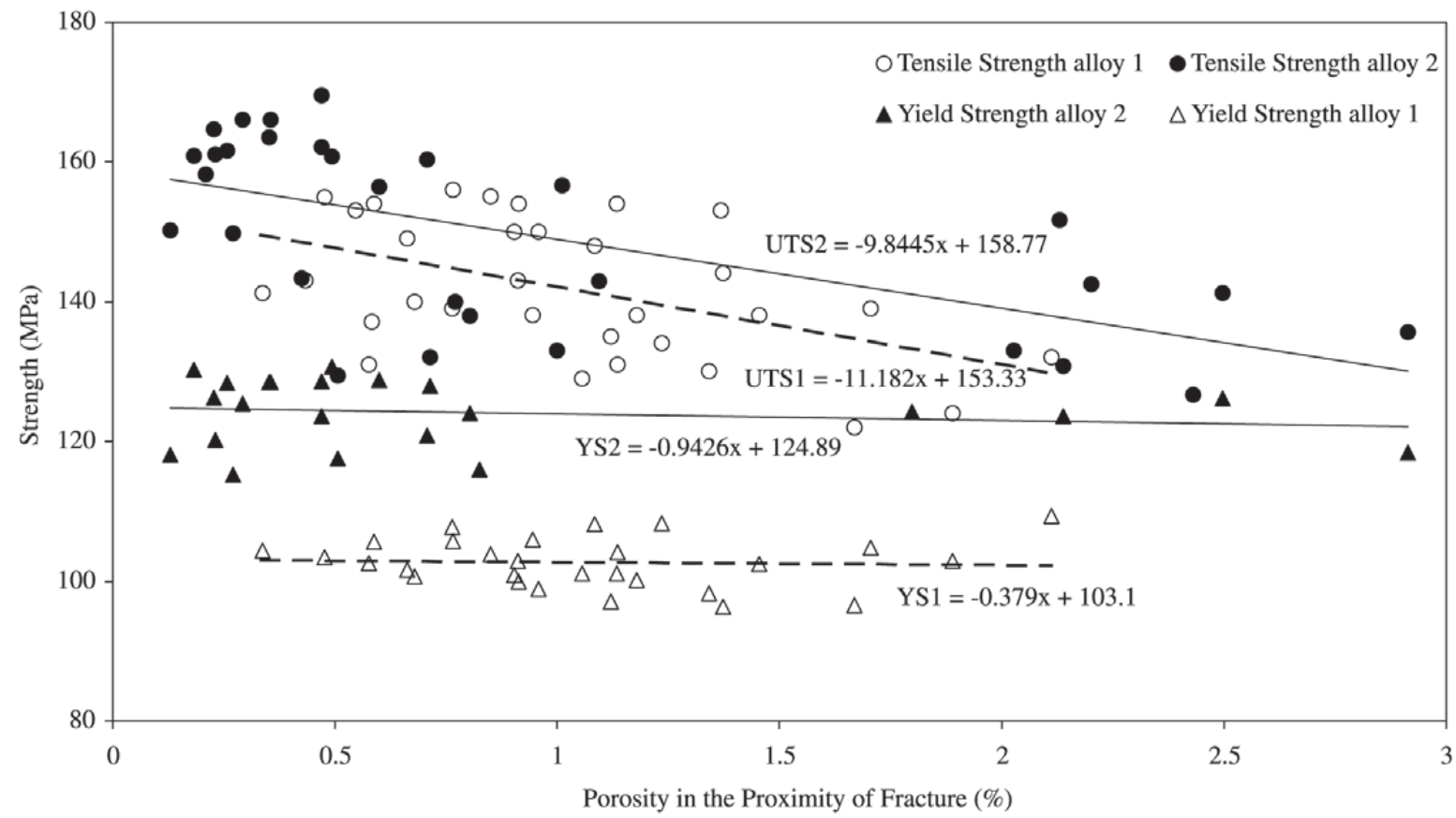

b)

Figure 6. a)Tensile strength, yield strength and elongation rate as a function of the volumetric porosity near the fracture surface of the two alloys; b) Tensile strength and yield strength as a function of the volumetric porosity near the fracture surface of the two alloys. Rm is the tensile strength corrected by a factor of 1.5. Ry is the yield strength corrected by the area of pores. 


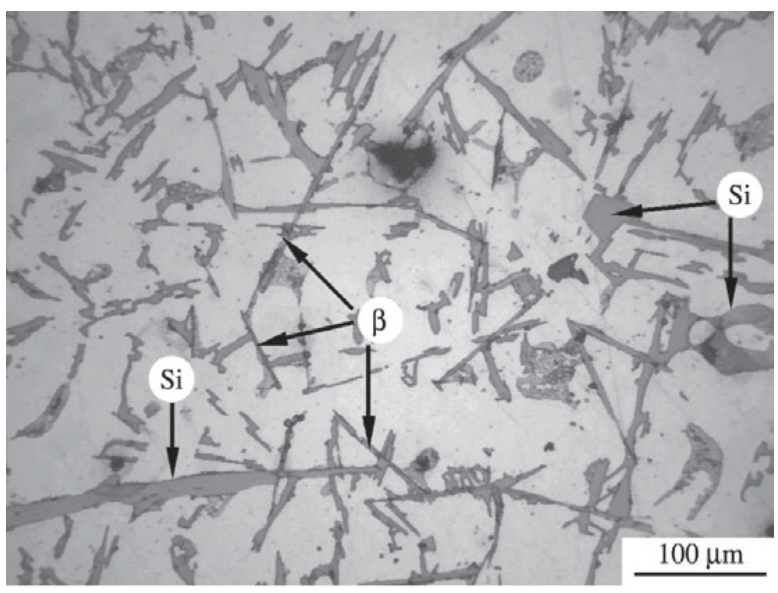

a)

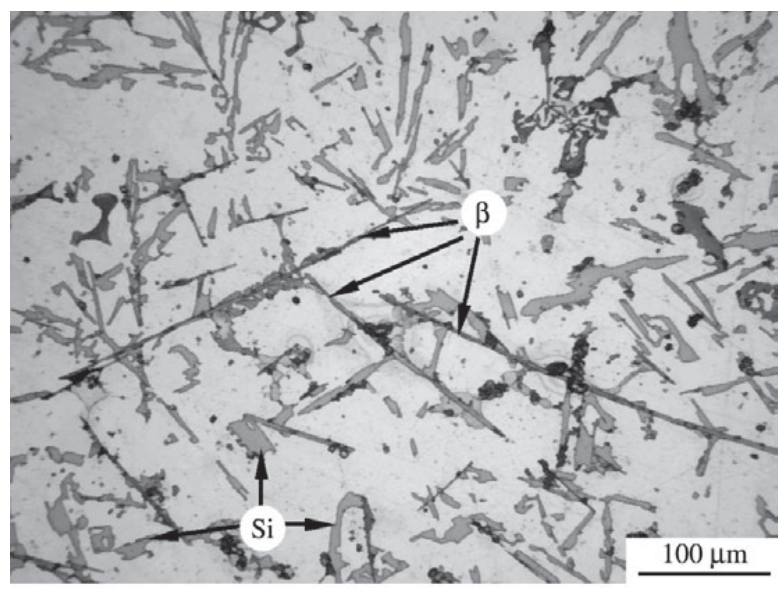

b)

Figure 7. Micrograph of the alloys studied, showing the $\beta$ phase present. a) alloy $1 ; b)$ alloy 2 .

\subsection{Fracture of particles:}

Figure $8 \mathrm{a}$ and $8 \mathrm{~b}$ show the shape of the $\beta-\mathrm{Al}_{5} \mathrm{FeSi}$ phase and $\mathrm{Si}$ particle fractures. The metallographic image indicates the direction of the applied load.

Figure $8 \mathrm{c}$ reveals broken particles next to the fracture, while Fig. $8 \mathrm{~d}$ and $8 \mathrm{e}$ show the effect of isolated pores on the particles.

\section{Discussion}

It is widely accepted that the mechanical properties of aluminum casting alloys depend on microstructural characteristics such as the dendritic cell size, grain size, silicon size in the eutectic Al-Si, and the size and morphology of the $\beta-\mathrm{Al}_{5} \mathrm{FeSi}$ phase, as well as on the pores and inclusions. The available literature considers these factors simultaneously, which prevents the reader from clearly distinguishing their individual effects.

The experiments performed in the present work were carried out on a selected range of thermal parameters so as to obtain similar microstructures. Table 3 lists the dendritic cell sizes of the alloys involved in this study. In the case of alloy 1 , the average dendritic cell size was $34.8 \mu \mathrm{m}$, while alloy 2 showed smaller cells with an average size of $28.57 \mu \mathrm{m}$.

Dendritic cell size exerts a similar effect on the mechanical properties of 380 and 356 aluminum alloys, according to Spear and Gardner ${ }^{15}$, and the increase in dendritic cell size from $28.6 \mu \mathrm{m}$ to $34.8 \mu \mathrm{m}$ may have affected the tensile strength by up to $3 \%$ without affecting the yield strength. The conditions used by Spear and Gardner were such that an increase in dendritic cell size was accompanied by an increase in porosity. Therefore, it is reasonable to suppose that the actual effect of larger dendritic cell size on the mechanical properties, within the size range considered, was appreciably lower.

The average grain size, in equivalent diameter, was $4.97 \mathrm{~mm}$ in alloy 1 and 4.7 in alloy 2 .

Figure 5 shows the behavior of the tensile strength, yield strength and elongation versus the global volumetric porosity for the two alloys. As can be seen, both tensile strength and elongation decreased with increasing porosity.

Alloy 2 displayed a higher tensile strength with every porosity value, a behavior attributable to the smaller size of the dendritic cells ${ }^{15}$, smaller grain size and higher $\mathrm{Mg}$ and $\mathrm{Fe}$ content.

It should be noted that the $\mathrm{Si}$ content in alloy 2 was higher than in alloy 1 , and that it increased by $0.96 \%$. The Si forming the eutectic was about $0.84 \%$, since the Fe content increased by $0.24 \%$ and combined with $\mathrm{Si}$ to form $\beta-\mathrm{Al}_{5} \mathrm{FeSi}$ phase. The Fe content in alloy 2 and the cooling rate applied caused the Fe to combine with the Si almost completely, forming the $\beta-\mathrm{Al}_{5} \mathrm{FeSi}$ phase ${ }^{16}$.

The elongation results in Fig. 5 indicate that alloy 2, with a higher $\mathrm{Si}$ and $\mathrm{Fe}$ content, was less affected by every level of porosity. The mechanical properties of these alloys had so far been analyzed only in relation to global volumetric porosity. However, Fig. 9 shows that the pore distribution in the material analyzed here tended to increase towards the center of the plate center, following the orientation of solidification. Hence, it can be assumed that the highest values of volumetric porosity will be found in the central region of the tensile tested specimen, where the occurrence of a fracture is highly probable.

The dispersion value indicated in the graphs of Fig. 5 and 6a is normal for these alloys, even when they are cast in 


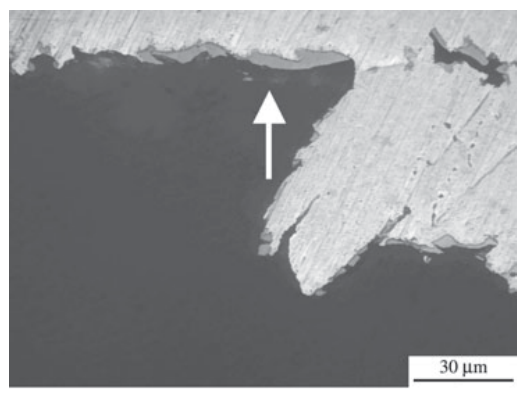

a)

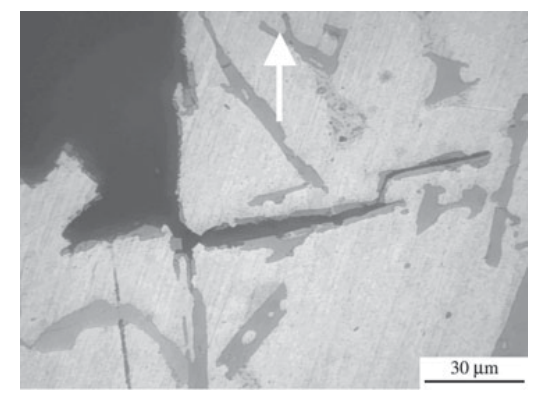

b)

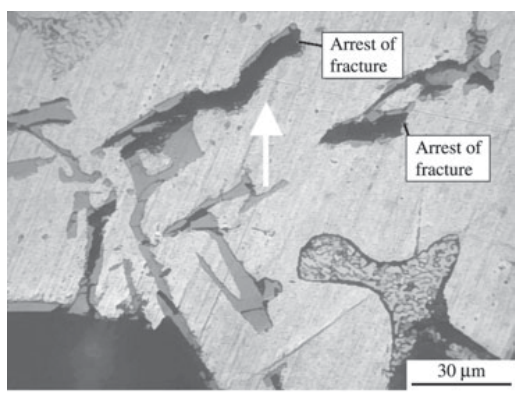

c)

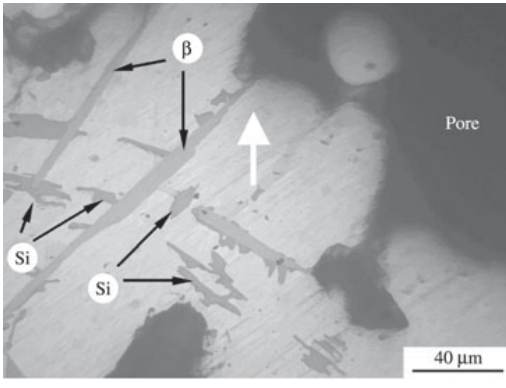

d)

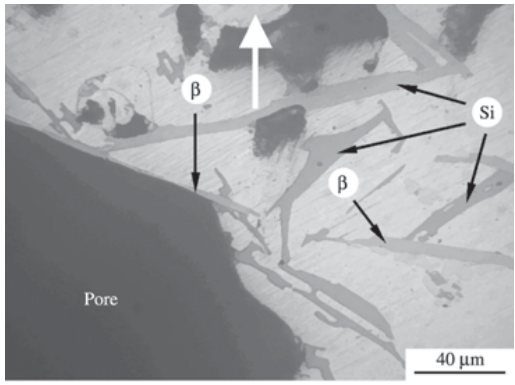

e)

Figure 8. a) e b) Micrograph of the fracture zone showing the form of fracture of $\mathrm{Si}$ and $\beta$ - $\mathrm{Al}_{5} \mathrm{FeSi}$ particles. c) Micrograph of broken particles of $\mathrm{Si}$ and $\beta-\mathrm{Al}_{5} \mathrm{FeSi}$ near the fracture; d) e e) Micrograph of the effect of isolated pores on $\mathrm{Si}$ and $\beta$ - $\mathrm{Al}_{5} \mathrm{FeSi}$ particles.

a permanent mold with a much finer microstructure ${ }^{6}$. Moreover, an initial analysis of Fig.6a and a comparison with Fig. 5 reveals that the volumetric porosity in the fracture is higher than the global volumetric porosity of the same sample ${ }^{17}$. This difference, therefore, confirms that the effect of porosity on the loss of mechanical properties per unit of porosity is overestimated when it refers to global volumetric porosity.

Due to the different compositions of the two alloys, one might expect a parallel displacement of the corresponding curves in a representation of tensile strength versus porosity, but not a change in slope. The slight difference in the slope of tensile strength versus the straight lines of porosity, in Fig. 6a, is too small to be attributed to the higher content of $\beta-\mathrm{Al}_{5} \mathrm{FeSi}$ phase and Si plate, as some authors affirm ${ }^{10}$.

Reports that attribute the increasing deterioration of mechanical properties to the combined action of porosity and $\beta-\mathrm{Al}_{5} \mathrm{FeSi}$ phase are confusing, since they consider a simultaneous change in these two microstructural characteristics. In the results shown here for the two alloys and for each level of porosity, only the composition and, consequently, the content of $\mathrm{Si}$ and $\beta-\mathrm{Al}_{5} \mathrm{FeSi}$ phase were changed.

In Fig. 6a, the alloy with much greater strength shows the least effect of porosity on the elongation values. This finding is congruent with that observed by Eady and Smith ${ }^{12}$ for 356 aluminum alloy. The alloy with greater elongation and low porosity, alloy 1 , having $0.75 \%$ of volumetric porosity in the fracture, displayed a lower elongation value than did alloy 2.

The hardening work coefficient of both alloys was measured, showing $n_{1}=0.36$ for alloy 1 and $n_{2}=0.40$ for alloy 2 . These values are average, since they decrease as the porosity increases. The higher value of $\mathrm{n}$ in alloy 2 has a greater capacity to distribute plastic deformation. This condition decreases the effect of area loss due to the presence of pores, thus making the alloy's ductility less sensitive to porosity.

It is worth noting that, although the tensile strength of the two alloys is affected similarly by the porosity, the elongation is more strongly affected in alloy 1 .

Figures 5 and 6a illustrate the yield strength versus both the global volumetric porosity and the volumetric porosity in the fracture.

In Fig. 6b, the loss of yield strength caused by porosity is explained mainly by the sample's loss of area. The tensile strength values cannot be explained, even though the "effective diameter" criterion proposed by Surappa ${ }^{5}$ was applied. However, the loss of area represented by the pores was undoubtedly not the only cause for the drop in tensile strength.

It is interesting to note that, regardless of their position in 
relation to the pore, the particles close to pores and separated from the fracture plane are not fractured (Fig. 8d and 8e), appearing to indicate that these pores did not behave as stress concentrators, which corroborates Surappa's observations.

On the other hand, the results obtained reveal a possible error in evaluating the effect of the global volumetric porosity, which may differ significantly from that of the porosity at the fracture surface, the latter being directly responsible for reducing the mechanical properties.

Figure 10 shows the tendency of the experiments performed here, relating the global volumetric porosity to the volumetric porosity in the fracture.

Some authors ${ }^{15,17}$ obtained lower dispersion values when correlating the mechanical properties with the volumetric porosity in the fracture. Such lower values were not observed
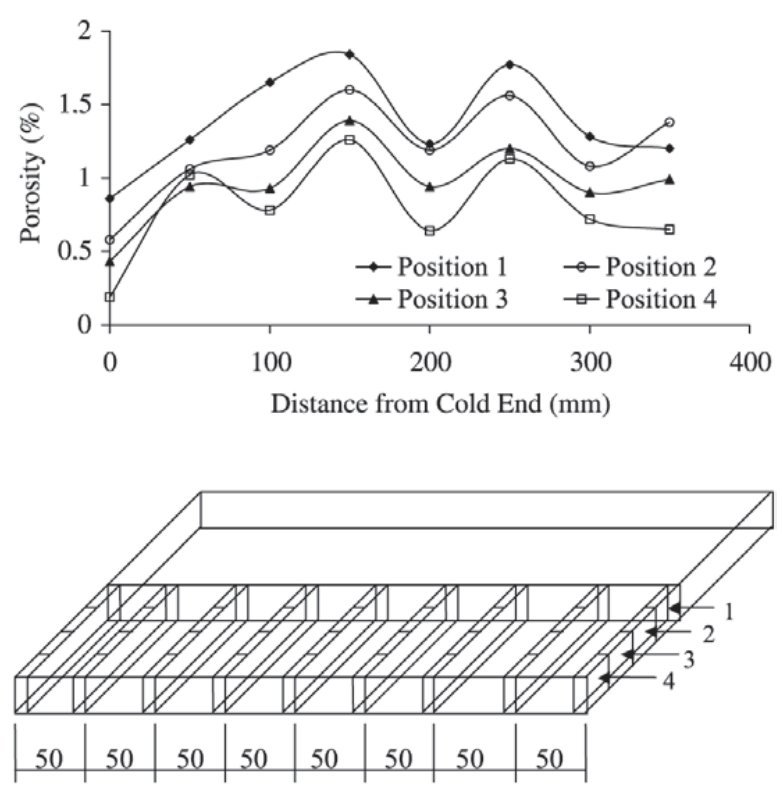

Figure 9. Volumetric distribution of porosity on the plate.

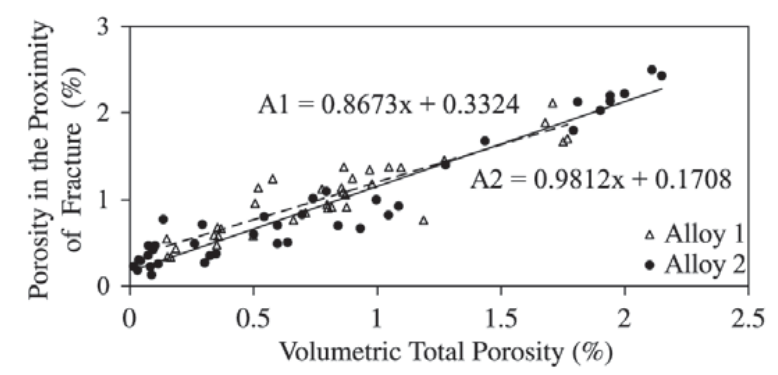

Figure 10. Correlation between global volumetric porosity and volumetric porosity in the fracture. in our study, although it should be noted that our measurements were not taken at the fracture but were obtained by weighing a volume $5 \mathrm{~mm}$ from the fracture surface. Measurements of smaller volumes (much closer to the fracture) showed no significant variations.

Figures $8 \mathrm{a}, 8 \mathrm{~b}$ and $8 \mathrm{c}$ show the characteristic microstructure in the zone of fracture. As can be seen, the damaged particles were restricted to a narrow site not wider than $150 \mu \mathrm{m}$. The fractured particles were oriented mostly along the major axis nearly perpendicular to the direction in which the load was applied. This situation is similar to that described by Samuel ${ }^{3}$ for 319 aluminum alloy, but contrary to that observed by Cáceres ${ }^{17}$ in 356 aluminum alloy. In the latter's report, the fractured particles were oriented with their major axis aligned approximately in the direction of the applied load. This orientation was also found in other cases of alloys with a ductile matrix ${ }^{18,19}$.

These findings appear to indicate that the particle damage models for ductile alloys, such as the one proposed by Cáceres ${ }^{17}$, do not apply to alloys with low elongation values, e.g., 319 and 380 aluminum alloys, since Cáceres adopted the "fiber-loading" mechanism proposed by Kelly and Davies ${ }^{20}$, which involves the transversal fracture of particles whose major axis is aligned with the direction of the applied load.

\section{Conclusions}

Although this study involved 380 aluminum alloy, our conclusions are not limited to this material.

- The fact that the distribution of porosity was not random invalidates global volumetric porosity as the determining parameter for porosity-related deterioration of the alloy's mechanical properties.

- Correlating mechanical properties under tensile stress to global volumetric porosity leads to an overestimation of the effect of porosity on the deterioration of these properties, since fracture porosity (usually higher) rather than global volumetric porosity is directly responsible for this deterioration.

- No fixed ratio exists between global volumetric porosity and volumetric porosity in the fracture, since this ratio depends on local conditions of solidification. Because the ratio between the two porosities cannot be preestablished, it is impossible to establish the aforementioned overestimation.

- The effect of porosity on yield strength may be attributed basically to the loss of resistant area resulting from the presence of pores.

- Because fracturing usually occurs in the area with the highest degree of porosity, it is evidently determined mainly by porosity.

- The deterioration of tensile strength remains constant 
even when the resistant area in the sample is corrected by porosity effect, indicating that the effect is not solely attributable to the loss of area in the tested section of the material.

- The alloys' variation in ductility appears to be more closely related with the hardening work coefficient than with the presence of brittle phases.

- The model proposed by Cáceres for brittle particle damage is not applicable to low ductility alloys.

\section{References}

1. Samuel, A.M.; Samuel, F.H. Journal of Materials Science, v. 30, p. 4823, 1995.

2. Radhakrishna; Seshan; Seshadri, M.R. Transactions Indian Inst. Metals, v. 34, p. 169, 1981.

3. Samuel, A.M.; Samuel, F.H. Metallurgical and Materials Transactions A. v 26a , p. 2359, 1995.

4. Surappa, M.K.; Blank, E.; Jaquet, J.C. Scripta Metallurgica, v. 20, p.1281, 1986.

5. Cáceres, C.H. Scripta Metallurgica et Materalia, v. 32, n. 11, p. 1851, 1995.

6. Wang, L.; Makhlouf, M.; Apelian, D. AFS Transactions, p. $675,1995$.

7. Cáceres, C.H.; Davidson, C.J.; Griffiths, J.R.; Wang, Q.G. Metallurgical and Materials Transactions A, v 30 A, p. 2611, 1999.

8. Wang, Q.G.; Cáceres, C.H.; Griffiths, J.R. AFS Transac- tions, p. 131, 1998.

9. Vorren, O.; Evensen, J.E.; Pedersen, T. B. AFS Transactions, p. 459, 1984.

10. Murali, S.; Raman, K.S.; Murthy, K.S.S. AFS Transactions, p. 1175, 1996.

11. Cuyás, J.C.; Mugica, G.W.; Tovio, D.O.; González, A.C. "Jornadas SAM 2000 - IV Coloquio Latinoamericano de Fractura y Fatiga”, Neuquén Argentina, v. 1, p. 191, agosto/2000.

12. Eady, J.A.; Smith, D.M. Materials Forum, v. 9, n. 4, p. $217,1986$.

13. Tovio, D.O.; Mugica, G.W.; González, A.C.; Cuyás, J.C. AFS Transactions, p. 457, 2001.

14. Hatch, J.E. Aluminum Properties and Physical Metallurgy, American Society for Metals 9 th Edition, p. 35, 1999.

15. Spear, R.E.; Gardner. AFS Transactions, v. 71, p. 209, 1963.

16. Shumacher, J.J.; González, A.C.; Cuyás, J.C. Congreso Bolivariano de Ingeniería Mecánica, in press, julio/2001.

17. Cáceres, C.H.; Griffiths, J.R. Acta Materalia, v. 44, n. 1, p. 25, 1996.

18. Le Roy, G.; Emburg, J.D. ; Edward, G.E.; Asbhy, M.F. Acta Metallurgica, p. 1509, 1981.

19. Walli, K.; Saario, T.; Torronen, K. International Journal of Fractura, p. 201, 1987.

20. Kelly A.; Davies G.J. Metal Review, v. 10, p. 21, 1967. 
